\title{
Application of Portfolio Theory in Controlling Supply Chain Crisis
}

\author{
Benxin Lao ${ }^{1}$, Ningjie Liu ${ }^{2}$ \\ 1.ERP Laboratory, Guangxi University of Finance and Economics, Nanning, \\ China, 530003, lbxwz@163.com \\ 2.Industrial and Commercial Management, Guangxi University of Finance and \\ Economics, Nanning, China, 530003, Inj1213@126.com
}

\begin{abstract}
Supplying chain cooperation has already become an important strategy that enterprises use to tackle market competition; however, the supply chain crisis caused by supply chain risk makes the supply chain operation of enterprises very fragile. This paper applies Portfolio Theory to explain the suppliers' combination plays an important role in dispersing the supplying chain risk and controlling its crisis, and point out, on the basis of analyzing the suppliers' expected return and risk, through choosing certain amount of suppliers and distributing the proportion of volume of purchase rationally, enterprises can find the efficiency front of suppliers combination.
\end{abstract}

\section{Introduction}

Home and abroad scholars have many research results on supply chain risk, including the qualitative and the quantitative. However, as supply chain system is a complicated system and its risk is very difficult to define, totally qualitative or totally quantitative method is all very difficult to be applicable in practical application. Portfolio Theory is a better risk controlling method combined nature and ration together, being widely applied to the investment field, but people have not realized its application value in controlling supply chain risk. This paper plans to probe into the application of Portfolio Theory in controlling supplying chain crisis.

\section{Portfolio Theory}

Portfolio theory is a systems approach that studies how to assign the fund available on more assets in various uncertain situation, in order to seek the most appropriate \& satisfactory assets combination, under which different kinds of investor can accept

Please use the following format when citing this chapter:

Lao, B., Liu, N., 2007, in IFIP International Federation for Information Processing, Volume 251, Integration and Innovation Orient to E-Sociely Volume1, Wang, W. (Eds), (Boston: Springer), pp. 9-16. 
return that match the risk. The start of Portfolio Theory can be traced back to Harry Markowitz's article entitled "Portfolio Selection" published in 1952, and the later (1959) monograph of the same name published.

Portfolio Theory introduces the concept of expect and variance in statistics into the research on assets combination. It assumes the probability of return ratio is definite and measures the mean deviation that variable of random return ratio deviates the average return ratio. It proposes the thought of measuring the prospective returns with expectation of the return ratio of the assets, of measuring the risk with the standard deviation of the assets return, of making the risk quantitative.

Illustrate Portfolio Theory's main conclusion in return and risk with examples as follows:

\subsection{Return and risk of two-asset portfolio}

(1) Two-asset portfolio return

$$
E\left(a R_{A}+b R_{B}\right)=a E\left(R_{A}\right)+b E\left(R_{B}\right)
$$

a, b is weight of asset A, B respectively, $R_{A}, R_{B}$ is return of asset A, B respectively.

(2) Two-asset portfolio variance (risk)

$$
\operatorname{Var}=a^{2} \sigma_{A}^{2}+b^{2} \sigma_{B}^{2}+2 a b \rho_{A B} \sigma_{A} \sigma_{B}
$$

This variance is formed by two parts: (1) $\left(\mathrm{a}^{2} \sigma^{2}{ }_{A}+\mathrm{b}^{2} \sigma_{B}^{2}\right)$ is the sum of variances of $A$ and $B$ two assets as the weight with the square of every assets. It reflects an impact of every asset's respective risk over the combination risk; (2) $2 a b \rho_{A B} \sigma_{A} \sigma_{B}$ (covariance item) is the risk of portfolio influenced by two assets' mutually affects and common movement. The size of this kind of influence is reflected by $\rho_{A B}$ (correlation coefficient). When $A, B$ two assets are not correlated perfectly $\left(0<\rho_{A B}<1\right)$, investment combination of minimum risk can be found; When $A, B$ two assets are negatively correlated $\left(-1 \leq \rho_{A B}<0\right)$, investment combination can reduce the investing risk more.

Therefore, so long as the assets returns are not completely positively correlated, portfolio can reduce the risk of investment; this is the risk dispersion effect caused by portfolio.

\subsection{Return and risk of $\mathrm{N}$-asset portfolio}

(1) $\mathrm{N}$-asset portfolio return

$$
E\left(R_{p}\right)=\sum_{i=1}^{N} X_{i} E\left(R_{i}\right)
$$

$\mathrm{X}_{\mathrm{i}}$ is the weight that asset $\mathrm{i}$ takes up the asset portfolio, $\mathrm{R}_{\mathrm{i}}$ is return of asset $\mathrm{i}$.

(2) $\mathrm{N}$-asset portfolio variance(risk)

$$
\operatorname{Var}=\sum_{i=1}^{N} X{ }^{2}{ }_{i}{ }^{2}{ }_{i}+\sum_{i=1}^{N} \sum_{j \neq i}^{N} X_{i} X_{j} \rho_{i j} \sigma_{i} \sigma_{j}
$$


As the same to two-asset portfolio, part I is a contribution to the portfolio's variance that every asset's own variance does, reflecting the risk state of every asset and its impact on the portfolio's risk; part II (covariance item) is the contribution to the portfolio's variance caused by each asset's mutual interaction and mutual influence. $\rho \mathrm{ij}$ is the correlation coefficient between asset $\mathrm{i}$ and asset $\mathrm{j}$.

Formula (4) is a summation of N2 item, among them part I takes up N items and part II takes up N2-N items. When $\mathrm{N}$ is bigger, the covariance item (Part II) should be far greater than the variance item (Part I). Therefore, when there are more assets projects in the asset portfolio, the interaction and influencing each other among the assets is the main risk source of portfolio. That is to say, increasing the assets figure, portfolio can reduces greatly, and even dispels the specific risk that each asset causes, i.e. non- systematic risk, finally. But the risk caused by interaction among all assets, i.e. the systematic risk can not be dispelled with the increase of $\mathrm{N}$. The systematic risk refers to the whole uncertainty that will exert an influence on all returns of the assets; it is the result of whole economic situation and the political situation change.

Generally speaking, if want to reduce the risk effectively, 10 kinds of assets is necessary; 15 kinds of assets are better quantity. But does not say it is the better that assets are the more. Further increasing of assets items can only increases the difficulty of management and trade expenses, but not reduces the risk effectively. ${ }^{1}$

\section{Application of portfolio theory in controlling supply chain crisis}

Today, the market competition is no longer a competition between enterprises and enterprises, but a competition between the supply chains. This is accepted by more and more enterprises already. Supply chain cooperation and supply chain alliance become the strategic choice that a lot of enterprises use for replying the market competition in recent years. It can not only obtain scale merit, but also can maximize favorable factors and minimize unfavorable ones, enable each enterprise to give play to one's own relative advantage, obtain one's own no or relatively weaker ability at the same time. We can say, supply chain cooperation is a kind of two-win or multiwin cooperation, and is enterprise's inevitable choice in the environment that modern science and technology develop violently, and market competitions become fierce. However, supply chain cooperation also is fragile. Once supply chain rupture, the losses caused to enterprise will be very serious. In 2003, according to Gartner Group's (U.S.A.) prediction, there is one in every five enterprises will be influenced for the reasons that supply chain is cut off in various forms. In these influenced enterprises, $60 \%$ will end up with going bankrupt. In addition, the transition on the commercial mode of a lot of enterprises has caused them to the change of the supply chain risk situation. For example, 'simplify measure', 'out sourcing' and reducing suppliers have become an overall trend, and all these will make supply chain more and more delicate.

Supply chain is formed by a lot of nodal enterprises which are all independent economic subjects. As rational people of economy, it is their instinct and excited to chase one's own interests biggest. Usually, key enterprises will be in the surging 
position in supply chain cooperation, but if it can't give consideration to the interests of other nodal enterprises and make them satisfied, they would change direction and cooperate with other enterprises for the economic reason. Thus bring crisis to the supply chain.

What is called supply chain crisis? It means in the course of supplying chain operation, uncertain major accidents influence the stability of supply chain and even lead supply chain system to disintegrate seriously, thus may leave enormous loss and damage to the products, service, fund and reputation in the whole supply chain. Why does the Supply chain crisis produce? Besides factor of interests' distribution, there are a lot of other factors. We can divide and summarize them as two classes of the external risk and endogenous risk. Among them,

The external risks include: (1) Policy risk; (2) Legal risk; (3) Industry's environmental risk; (4) Technology changes risk; (5)Natural disaster risk; (6)Market fluctuations risk, etc..

The endogenous risks include: (1) Morals risk (credit risks) of the cooperative partner; (2) Ability risk of the cooperative partner; (3) Fund risk of the cooperative partner; (4) Information transmission risk of the cooperative partner; (5) Trust crisis of the cooperative partner, etc..

According to the portfolio theory, the endogenous risks belong to nonsystematic risk in the supply chain operation, caused by the supply chain structure and problem of management, and can be controlled effectively through the suppliers' combination; the external risks belong to systematic risk in supply chain operation. They are the risks more difficult for member enterprises to control. Its difficulty relates to the range of risk--the greater the range is, the greater the difficulty is.

\section{Methods of controlling supply chain crisis effectively}

\subsection{Setting up elastic supply chain}

According to the portfolio theory, so long as the returns of the suppliers are not relevant perfectly or relevant negatively, the risk of the supplier combination can be dispersed and reduced. These suppliers are usually independent. They can be the same area; also can be different areas or different supply channel. In addition, only the suppliers of a supply chain reach certain amount, the risk can be dispersed effectively. What is this best amount? It is usually relevant to the purchase scale of enterprises. But just as assets can not be too much, the suppliers we choose can not be too much either. If not, suppliers' combination can't reduce the risk. It may causes greater risk because of failure management, failure control, or increasing uncertain factor. Moreover, that too much suppliers is unfavorable to realizing purchasing scale merit.

In a word, "don't put all eggs in the same basket." Now, cutting down the supplier's quantity is becoming a trend in some large-scale enterprises. They aim to establish the partnership relation or strategic alliance with the suppliers by cutting down supplier's quantity. For example, Xerox reduces its supplier's quantity to 400 families from more than 5000; Zhongxing Telecom Co. (China) is implementing a 
project of "improving the concentration degree of purchasing", and its goal is to concentrate the amount of purchase of $80 \%$ on the first 50 key suppliers. But what we should pay attention to is that although these enterprises cut down their supplier's quantity, but their supplier's quantity still maintains at certain number. If is for lower costs or so-called consolidation relation, an enterprise cuts the supplier's quantity to little, even adopts 'Single Sourcing', that is to say, place all raw materials' purchase of a kind of product on a supplier, then the potential risk of its supply chain is very great. (2)

After the upper suppliers (including lower distributors) reach certain amount, supply chain becomes supply net. It is an elastic supply chain (Fig. 1).

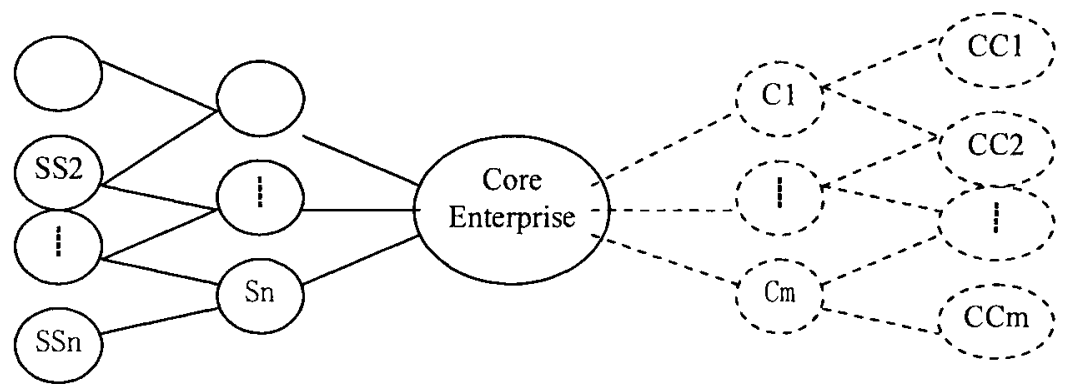

Fig.1 Elastic Supply Chain (Supply Net)

So when the upper (including the lower) nodal enterprises break away from the supply chain or other crises appear, other nodal enterprises or channels still guarantee the supply chain's operation normally. Certainly, at this time, enterprises should make a self-examination; look for the problem existing in supply chain management; take measures in order to prevent the further enlargement of the supply chain crisis.

\subsection{Looking for the efficiency front of suppliers combination}

The portfolio efficiency front theory points out: Investors seek the high return, but avoid the risk; on the basic of analyzing expected return, risk and relevance of investment combination, we can delineate the front of efficiency out, which includes investment combinations of realizing optimum equilibrium between risk and return; investors select the corresponding assets combination from the front of efficiency according to risk endurance and other restraint. We can infer that different supplier's combination it is, different efficiency it is. So, in order to find an optimum or effective supplier's combination, enterprises must be able to describe the expected return ratio and risks of each supplier and their combination quantitatively, and delineate out the efficiency front curve of a supplier's combination on this basis. Here, expected return ratio is the return ratio that a enterprise obtains from a supplier, can be expressed with the return rate of the purchase cost; The risk refers to the intensity that various uncertain accidents make the supplier expected return ratio to deviate from the average return. We can use the Level Analytic Approach, Fuzzy Analytic Hierarchy Process (Fuzzy-AHP) etc. to carry on comprehensive analysis to 
each supplier's possible morals risk, cut-off risk, ability risk (or performance risk), fund risk, etc.; then, estimate the probability of various expected return ratio; finally, use 'mean value - variance law' to calculate $E(R)$ and $\sigma$.

The following is the analysis on the efficiency front of two-supplier combination and $\mathrm{N}$-supplier combination.

(1)Efficiency front of two-supplier combination

Suppose as follows:

- $\mathrm{E}\left(\mathrm{R}_{\mathrm{A}}\right)=5 \%, \sigma_{\mathrm{A}}=6 \%$

$E\left(R_{A}\right)$ : the return ratio of supplier $A ; \sigma_{A}$ : standard deviation of supplier $A$.

- $\mathrm{E}\left(\mathrm{R}_{\mathrm{B}}\right)=9 \%, \sigma_{\mathrm{B}}=7 \%$.

$E\left(R_{B}\right)$ : the return ratio of supplier $B ; \sigma_{B}$ : standard deviation of supplier $B$.

- The proportion of the suppliers' combination is $50 \% \mathrm{~A}$ and $50 \% \mathrm{~B}$ according to volume of purchase.

Then, the expected return ratio and variance are calculated as follows:

$$
\begin{aligned}
E\left(a R_{A}+b R_{B}\right) & =a E\left(R_{A}\right)+b E\left(R_{B}\right) \\
= & 0.5 \times 5 \%+0.5 \times 9 \% \\
= & 7 \% \\
\operatorname{Var}\left(a R_{A}+b R_{B}\right) & =a^{2} \sigma_{A}^{2}+b^{2} \sigma_{B}^{2}+2 a b C O V_{A B} \\
& =a^{2} \sigma_{A}^{2}+b^{2} \sigma_{B}^{2}+2 a b \rho_{A B} \sigma_{A} \sigma_{B}
\end{aligned}
$$

In formula (6), COVAB $=\mathrm{E}(\mathrm{AB})$ - EAEB, is covariance of return ratio of supplier $A$ and $B ; \rho A B$ is the correlation coefficient of return ratio of supplier $A$ and $B$, reflecting the mutual effect of change of $A$ and $B$ two suppliers' return. The relation between $C O V A B$ and $\rho A B$ is:

$$
\rho_{A B}=\frac{C O V_{A B}}{\sigma_{A} \sigma_{B}}
$$

$$
\begin{aligned}
\operatorname{Var}\left(a R_{A}+b R_{B}\right) & =0.5^{2} \times 0.06^{2}+0.5^{2} \times 0.07^{2}+2 \times 0.5 \times 0.5 \times 0.1357 \times 0.06 \times 0.07 \\
& =0.00241 \\
\text { If } \operatorname{COV}_{A B} & =0.057 \%, \text { then } \rho_{A B}=0.1357,
\end{aligned}
$$

Standard deviation. $\sigma_{\mathrm{P}}=\sqrt{\operatorname{Var}\left(a R_{A}+b R_{B}\right)}=4.91 \%$

By same means, we can get every $\mathrm{E}(\mathrm{R})$ and $\sigma$ of $\mathrm{A}, \mathrm{B}$ two-supplier combination, which is made up in a random proportion according to the volume of purchase. All these suppliers' combinations form a supplier combination set. Regarding $\sigma$ as abscissa, E ( R) as ordinate, copying out all group data on the coordinate, we can get a curve which connects A and B (Fig. 2): 


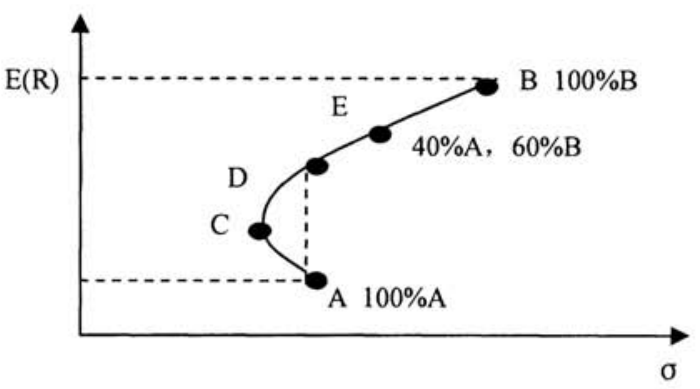

Fig.2 Efficiency front of two-supplier combination

Different points on the curve ACEB represents a A,B two-supplier combination of different allocation proportion according to volume of purchase (for example, E represents a proportion of $40 \% \mathrm{~A}$ and $60 \% \mathrm{~B}$ ). Enterprises can choose the points appropriately according to their need, but the line segment CEB is the efficiency front for making up a suppliers' combination, i.e. under the situation with certain risk, expected return is the highest; or under the situation with certain expected return, the risk is the lowest.

(2)Efficiency front of $\mathrm{N}$-supplier combination

$\mathrm{E}(\mathrm{R})$ and $\sigma$ of every $\mathrm{N}$-supplier combination can be calculated with formula (3), formula (4) respectively. $\mathrm{N}$ suppliers can form a lot of combinations; the set that these suppliers' combinations make up is an area on a plane (Fig. 3).

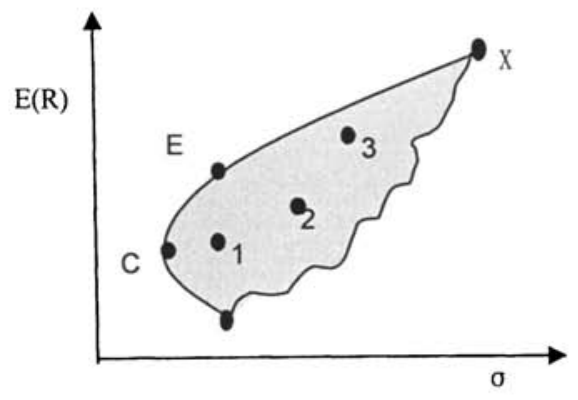

Fig.3 Efficiency front of $\mathrm{N}$-supplier combination

In this area, point 1 may be the combination formed by 10 suppliers; point 2 may be the combination formed by 15 suppliers, and so on. Enterprise can choose its favorable set in this area arbitrarily. However, the curve CEX is obviously the efficiency front of the supplier' combination. Comparing with the within area of shade, supplier's combinations on CEX curve have higher expected return ratio on the same risk, or have lower risks under the same expected return ratio. 


\section{Conclusion}

Although the portfolio theory is based on the investment field, its risk analysis and risk control method is suitable for supply chain management too, especially very meaningful for controlling supply chain crisis. According to portfolio theory, if suppliers chosen are up to certain amount and the expected return that enterprise win from them are not relevant perfectly or relevant negatively, the risk of the supplier combination can be dispersed and reduced, and supply chain crisis can be controlled effectively. The composition of the suppliers' combination embodies in different of suppliers' amount and different of distribution proportion of purchase volume among different suppliers. The supplier quantity choice will be decided to the scale of the enterprise purchases, and the proportion of purchases can be optimized through the operation method and tool. On the basic of analyzing the supplier's expected return and risk, calculating the $\mathrm{E}(\mathrm{R})$ and $\sigma$ of every kind of suppliers ' combination, enterprise can get different points on the coordinate. All these points form a set of supplier's combination. The front of efficiency only includes a small part of the possible supplier's combination, i.e. the curve above the left of the set. The supplier's combinations on the efficiency front curve are the best choice for enterprises.

\section{References}

1. P.L Song, "Study on the modern portfolio theory", Guizhou finance and economics institute journal, 2000 (3), $\mathrm{P} 14-17$ (in Chinese)

2. Y.G Cao, Securities investment study, Beijing University Press, 1993, P119-136(in Chinese)

3. Y.H Liang, "Research on crisis forewarns index system of supply chain", Information magazine, 2006(5), P24-25 (in Chinese)

4. Stauffer, "Risk: the weak link in your chain", Harvard Management Update, March 2003

5. Formation Workshop, "Enterprise and supply chain risk", Management \&Continuity Forum, America, Feb 19, 2003

6. Alain Halley, Jean Nollet," The supply chain: the weak link for some preferred supplier", The journal of supply chain management, summer, 2002, P39-47 